\title{
MORFOESTRUTURA E DISPERSÃO SEDIMENTAR NA BACIA OCEÂNICA AO LARGO DA BACIA PARÁ-MARANHÃO, ATRAVÉS DA INTERPRETAÇÃO DE PERFIS DE SÍSMICA MULTICANAL
}

\author{
MORPHOSTRUCTURE AND SEDIMENTARY DISPERSION IN BASIN \\ OCEANIC TO WIDE PARÁ-MARANHÃO BASIN, THROUGH THE \\ INTERPRETATION OF MULTI-CHANNEL SEISMIC PROFILES
}

\author{
Ricardo Lincoln de Azevedo \\ Departamento de Geografia, Universidade do Estado do Rio de Janeiro. \\ Rua São Francisco Xavier, 524, Pavilhão João Lyra Filho, Bloco F, sl. 4006, \\ $4^{\circ}$ andar, Maracanã, Rio de Janeiro/RJ. Cep: 20550-900, Brasil. \\ E-mail:ricardo.lincoln@gmail.com,ppgeo.uerj@gmail.com
}

\section{Informações sobre o Artigo}

Data de Recebimento:

14/01/2014

Data de Aprovação:

05/03/2014

\section{Palavras-chave:}

Equatorial Atlântico, geomorfologia submarina, tectônica gravitacional, fácies sísmicas.

\section{Keywords:}

Atlantic equatorial, submarine geomorphology, gravitational tectonics, seismic facies.

\section{Resumo}

O presente artigo está inserido no contexto de estudos relativos ao segmento equatorial da Margem Continental Brasileira, concentrando a pesquisa no entendimento da sedimentação da bacia oceânica situada ao largo da Bacia Pará-Maranhão. A área em estudo destaca-se pela presença do cinturão de dobramentos associado à tectônica gravitacional, situado na região do talude e elevação continental, estendendo-se desde a Bacia Barreirinhas, passando pela Bacia Pará-Maranhão até alcançar o Cone do Amazonas; pelas intrusões vulcânicas associadas aos inúmeros montes submarinos que exercem forte influência sobre a sedimentação; pelo lobo deposicional recente de grande extensão composto de sedimentação semelhante à do Cone do Amazonas. A pesquisa busca o entendimento da sedimentação da bacia oceânica, com ênfase desde o Terciário ao Recente, a partir da análise e interpretação de linhas de sísmica de reflexão multicanal 2D do Projeto Leplac. Neste sentido, foram identificados os principais eventos discordantes, estes por sua vez foram correlacionados a eventos globais de variação do nível do mar, à história tectônica andina e ao tectonismo oceânico. Em seguida, procedeu-se à caracterização das sismofácies objetivando o entendimento dos processos deposicionais ocorridos na área em estudo; e por fim, se estabeleceu a compreensão da interferência das estruturas vulcânicas nas sequências deposicionais.

\footnotetext{
Abstract

The present paper is inserted in the context of studies relative to the equatorial segment of the Brazilian Continental Margin, concentrating the research on the understanding of the sedimentation of the oceanic basin near the Pará-Maranhão Basin. The area stands out for the presence of the fold belt associated with
} 
gravitational tectonics and it's placed in the slope and continental elevation, extending from the Barreirinhas Basin, passing by the Pará-Maranhão Basin until reaching the Amazonas Cone. Volcanic intrusions associated to several submarine hills exercise strong influence on the sedimentation; and the recent deposicional lobe has great extension and has similar sedimentation to the one of the Amazonas Cone. The search research understand the oceanic basin sedimentation, with emphasis on the Tertiary to the Recent and is based on the analysis and interpretation of 2D multichannel seismic lines of Leplac Project. In this sense, the main discordant events were identified, these for its time, were correlated with of the global events of change of sea level, for example, those relative ones to the Andean tectonic history and the Oceanic tectonism . Then proceeded to characterization of the seismic facies aiming at understanding the depositional processes that occurred in study area, finally understanding interference of the volcanic structures in the depositional sequences.

\section{Introdução}

O presente artigo está inserido no contexto de estudos relativos ao segmento equatorial da Margem Continental Brasileira, concentrando a pesquisa no entendimento da sedimentação da bacia oceânica situada ao largo da Bacia Pará-Maranhão, com ênfase desde o Terciário ao Recente. A área destaca-se pela presença notável do cinturão de dobramentos associado à tectônica gravitacional, situado na região do talude e elevação continental, estendendo-se desde a Bacia Barreirinhas, passando pela Bacia Pará-Maranhão até alcançar o Cone do Amazonas; pelas intrusões vulcânicas associadas aos inúmeros montes submarinos que exercem forte influência sobre a sedimentação; e pelo lobo deposicional recente de grande extensão composto de sedimentação semelhante à do Cone do Amazonas.

A área em estudo compreende a Bacia Oceânica localizada no Atlântico Equatorial ao largo da Bacia Pará-Maranhão, porção norte da plataforma continental brasileira, entre as latitudes $4^{\circ} \mathrm{S}$ e $6^{\circ} \mathrm{N}$ e as longitudes $40^{\circ}$ e $48^{\circ} \mathrm{W}$ de Greenwich. (Figura 1 ).

Em termos de objetivo geral, buscou-se o entendimento da sedimentação da bacia oceânica situada ao largo da Bacia Pará-Maranhão, do Terciário ao Recente, a partir da análise e interpretação de linhas de sísmica de reflexão multicanal do Projeto LEPLAC (Levantamento da Plataforma Continental Brasileira).

Foram identificados os principais eventos discordantes, que por sua vez foram correlacionados a eventos globais de variação do nível do mar, à história tectônica andina e ao tectonismo oceânico. Em seguida, procedeu-se à caracterização das sismofácies objetivando o entendimento dos processos deposicionais ocorridos na área de estudo; e por fim, estabeleceu-se a compreensão da interferência das estruturas vulcânicas nas sequências deposicionais.

\section{Material e Procedimentos Metodológicos}

\section{Material}

A realização do trabalho foi baseada na bibliografia disponível e na interpretação de perfis de sísmica de reflexão multicanal 2D do Projeto LEPLAC. Os perfis utilizados totalizam $2.000 \mathrm{~km}$ de levantamento regional realizados na Margem Atlântica Equatorial, cobrindo desde a plataforma externa, quebra da plataforma, estendendo-se até a Elevação do Ceará. O conjunto de dados é constituído por quatro linhas sísmicas na orientação dip, direção SW/NE, com 500 km de extensão cada e espaçamento de $100 \mathrm{~km}$ entre as linhas, 5010029, 5010030, 5010031, 5010032, respectivamente. (Figura 1).

\section{Procedimentos Metodológicos}

A partir da compilação do banco de dados no formato X, Y, Z, provenientes do ETOPO - 2 minute Worldwide Bathymetry/Topography Grids, Smith \& Sandwell (1997), confeccionou-se a malha dos dados, seguida de elaboração do mapa batimétrico da área em estudo. Logo após, foram tratados e filtrados os dados oriundos do Projeto LEPLAC, visando à confecção do mapa de navegação com pontos de tiro (shot points) dos respectivos levantamentos. Ambos os procedimentos foram gerados no programa Generic Mapping Tools (GMT). Em seguida, foram confeccionados mapas georreferenciados no programa Arqview ${ }^{\circledR}$ em uma base cartográfica comum, Projeção Policônica LEPLAC e Datum Planimétrico Córrego Alegre, visando à localização dos limites do deslizamento, das estruturas encontradas no interior das sequências deposicionais e do lobo de sedimentação recente. 

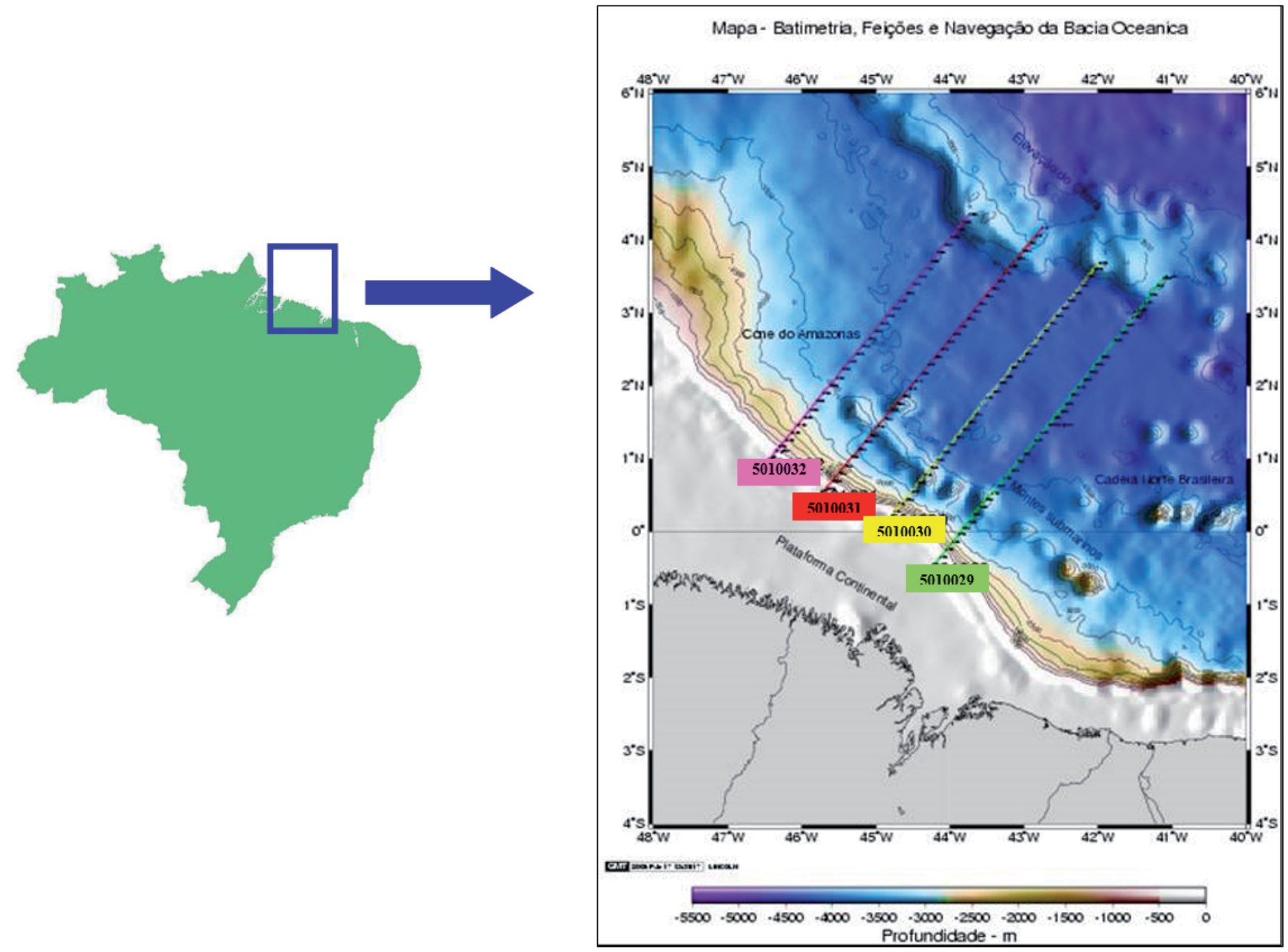

Figura 1 - Mapa de localização geográfica da área em estudo, seguido da batimetria, feições e traçado da navegação.

Os perfis de sísmica de reflexão multicanal 2D do Projeto LEPLAC foram carregados e interpretados no software Geographyx ${ }^{\circledR}$ (Landmark). Posteriormente, as linhas foram impressas e interpretadas sobre papel para facilitar a identificação das estruturas vulcânicas, a tectônica gravitacional, o sistema de falhas, as principais discordâncias regionais nas seções sísmicas e, por fim, a caracterização das sismofácies.

A análise tectono-sedimentar da área de estudo foi realizada segundo os princípios gerais da estratigrafia sísmica, possibilitando a identificação das principais sequências deposicionais, da plataforma externa, talude, sopé continental e profundidades abissais da margem continental equatorial, mediante as características das fácies sísmicas de cada unidade deposicional individualizada, que permitiu o entendimento dos eventos ocorridos e consequentemente, forneceu informações sobre o paleoambiente deposicional da área em estudo, conforme os conceitos de Mitchum Jr. et al. (1977), descritos por Severiano Ribeiro (2001) e Della Fávera (2001).

Para tanto, as sequências identificadas foram denominadas conforme as idades das respectivas Épocas geológicas, cada qual separada por superfícies refletoras de contato demarcadas com cores distintas. A descrição, interpretação geológica e identificação das respectivas sequências, foram possibilitadas a partir das informações quanto aos parâmetros de reflexão sísmica tais como: a configuração, a continuidade, a amplitude, a frequência das reflexões sísmicas, a velocidade intervalar, forma externa e associação areal da fácies sísmicas como também as associações tridimensionais de grupos de reflexões e padrão de estratificação. 


\section{Correlação Tentativa das Sequências Mapeadas com a Variação Global do Nível do Mar.}

Na ausência de uma malha de dados de poços em águas profundas na área em estudo e, portanto, de dados bioestratigráficos, que permitissem uma correlação entre o arcabouço das sequências deposicionais e os eventos conhecidos de variação global do nível do mar, Gomes (2000) realizou uma extrapolação de rastreamento e mapeamento sísmico, utilizando os dados do Projeto LEPLAC.

Durante este rastreamento foi verificada a continuidade dos horizontes pelo menos até a margem continental sudeste/sul, o que significa uma considerável extensão dos eventos, somente justificável a partir de rebaixamentos do nível marinho (relativo) de expressão continental. Em seguida foi realizada uma etapa de checagem cronoestratigráfica, a partir da comparação do exercício de rastreamento sísmico anterior com o mapeamento sísmico de supersequências e discordâncias limítrofes, realizado na Margem Continental Atlântica dos Estados Unidos, na região de Nova Jersei, com razoável amarração mediante análise de dados de poços do Deep Sea Drilling Project (DSDP), (POAG 1985; POAG et al., 1987). Nestes estudos foram identificados os principais eventos geológicos, paleobiológicos e paleoceanográficos dos últimos $84 \mathrm{Ma}$. Constatou-se que as discordâncias mapeadas na margem continental se encaixam adequadamente na sequência de eventos, após análise comparativa com o trabalho de Gomes (2000). As superfícies mapeadas são também cronoestratigraficamente correlatas às discordâncias I e IV identificadas por Gambôa et al.(1983), na porção sul da Bacia Oceânica do Brasil, junto ao poço DSDP-515.

Dessa maneira foram correlacionadas as idades relativas atribuídas aos horizontes mapeados com as idades de algumas das mais importantes discordâncias inter-regionais do Fanerozóico, apresentadas por Vail et al. (1977).

Da mesma forma, fez-se uma correlação tentativa das sequências mapeadas com a Carta de Ciclos Eustáticos Globais de Haq et al. (1988) (Figura 2). Esta Carta está baseada em documentação e datações de afloramentos de rochas marinhas em diferentes partes do mundo, o que a confere uma resolução muito maior do que a curva de Vail et al. (1977). Neste contexto, há estudos realizados por Souza Cruz (1995), na bacia de
Campos e Mendes (1994), na bacia de Sergipe-Alagoas, que demonstram uma perfeita correlação de eventos com a curva global de Haq et al. (1988).

\section{Resultados}

\section{Identificação dos refletores.}

As seis superfícies refletoras básicas marcadas com cores distintas, representando os limites de seis sequências sedimentares, situadas entre o embasamento oceânico e o fundo do mar estão supostamente associadas estratigraficamente, da base para o topo, da seguinte maneira:

A) Topo do embasamento: (Emb. - vermelha).

B) Cobertura sedimentar: superfície refletora Cretáceo Superior, sequência (S1-K - amarela); Paleoceno, sequência (S2-P - laranja); Eoceno, sequência (S3-E - verde); Oligoceno, sequência (S4-O - marrom); Mioceno, sequência (S5-M - azul); topo do Plioceno, sequência deposicional recente (S6- Pl) e Fundo do Mar (Fmar - verde-escura). (Figura 3).

\section{Sedimentação Recente.}

Em profundidades abissais, destacam-se as sismofácies subparalelas com reflexões de amplitude alta características de sedimentos hemipelágicos depositados próximo ao continente, passando em direção à bacia, a plano-paralelas contínuas. Esses atributos permitem inferir que a deposição dos sedimentos correspondentes processou-se em ambiente marinho profundo e de baixa energia.

No interior da sequência descrita acima, observase uma unidade sedimentar com morfologia lobular, quando vista de cima e, forma de lente quando no plano do perfil. Localiza-se entre a Cadeia de Montes Submarinos (CMS) e a Elevação do Ceará, com orientação NW/SE longitudinal à costa, com $500 \mathrm{~m}$ de espessura em média, ultrapassando os limites das linhas sísmicas estudadas.

Este lobo encontra-se sob uma coluna de água de 4.300m, apresenta menor extensão no perfil 5010029, cerca de $45 \mathrm{~km}$, aumentando gradativamente nas linhas centrais; 240 km no perfil 5010030, 250 km no perfil 
Morfoestrutura e Dispersão Sedimentar na Bacia Oceânica ao Largo da Bacia Pará-Maranhão

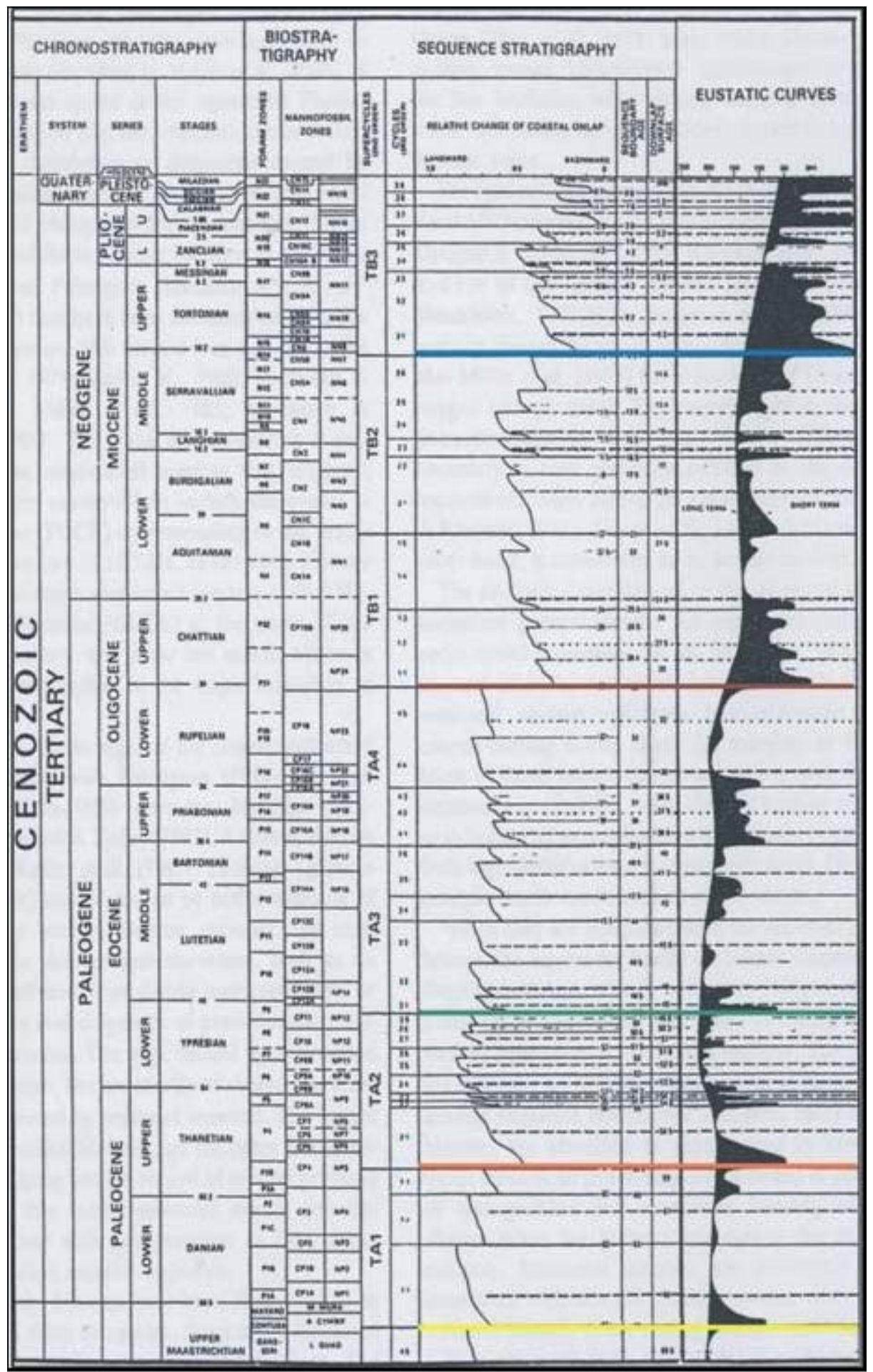

Disc. Mioceno

Disc. Oligoceno

Disc. Eoceno

Disc. Paleoceno

Disc. Topo Cretáceo

Figura 2 - Carta de ciclos eustáticos globais do Cenozóico Haq et al. (1988). As cores indicam uma provável correlação com as superfícies de discordância mapeadas na margem Equatorial Atlântica. (Adaptado de Gomes, 2000). 


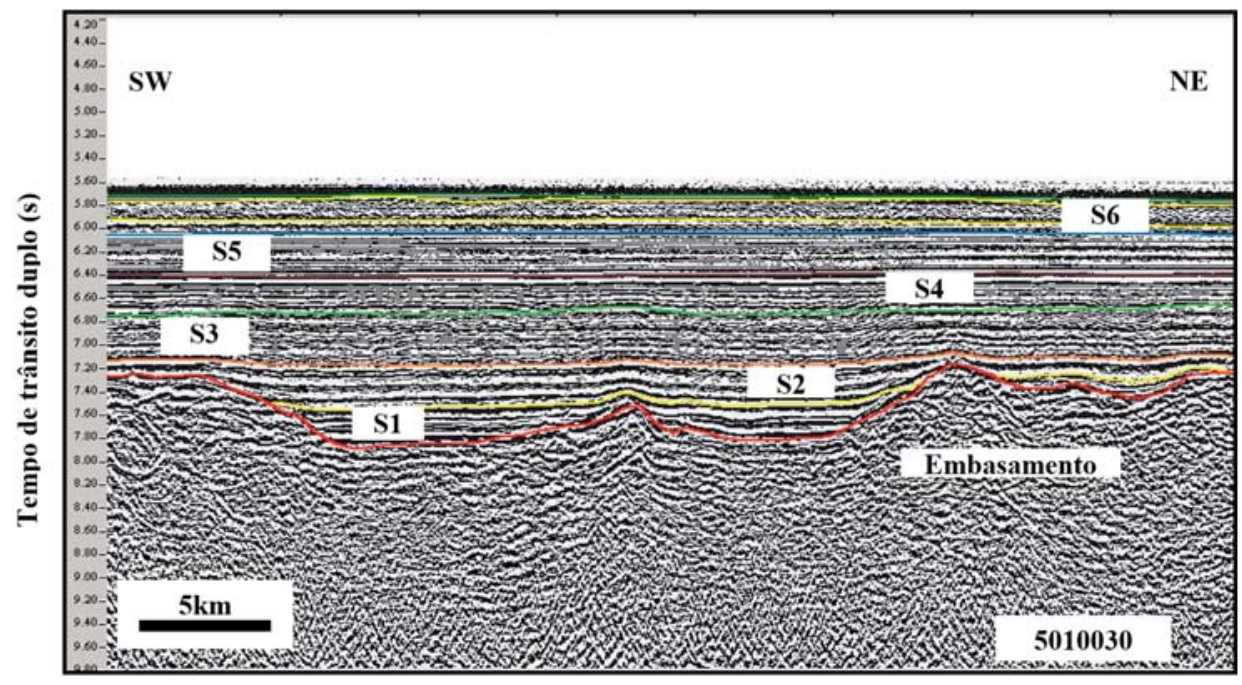

Figura 3 - Sequências deposicionais e respectivas superfícies refletoras.

5010031, diminuindo em direção ao perfil 5010032, adjacente ao Cone do Amazonas, onde apresenta uma extensão de 175 km, perfazendo uma área aproximada de $72.000 \mathrm{~km}^{2}$. (Figura 4).

O Lobo apresenta sismofácies variando entre o caótico e o hummocky em toda área de ocorrência, muito semelhante às sismofácies encontradas no cone do Amazonas, conforme análise dos perfis 5010021A e 5010022A não apresentados aqui, mas, são adjacentes aos perfis interpretados para este trabalho. Diretamente acima do lobo descrito, observa-se uma sequência deposicional extremamente delgada, depositada por último no fundo oceânico, com sismofácies plano-paralelas contínuas em toda a sua extensão, retratando sedimentação pelágica em toda a região.
Considerações relativas à proveniência de sedimentos e aos processos formadores da lente

Presume-se ser o Rio Amazonas o fornecedor de sedimentos que originou a deposição com morfologia lenticular presente na sequência Plioceno, devido à continuidade lateral prolongando-se em direção ao cone do Amazonas e à semelhança das sismofácies características encontradas, caótica e hummocky, Severiano Ribeiro (2001), tanto no lobo, quanto no cone propriamente dito. A principal fonte de sedimentos formadores do lóbulo parece ter sido o cinturão dos Andes, uma vez que este é a principal fonte de sedimentos predominantes na área de estudo e na Elevação do Ceará. Esta sedimentação é resultante da decomposição química e desagregação mecânica, principalmente de rochas pós-arqueanas andinas (Dobson et al., 2001). (Figura 5).

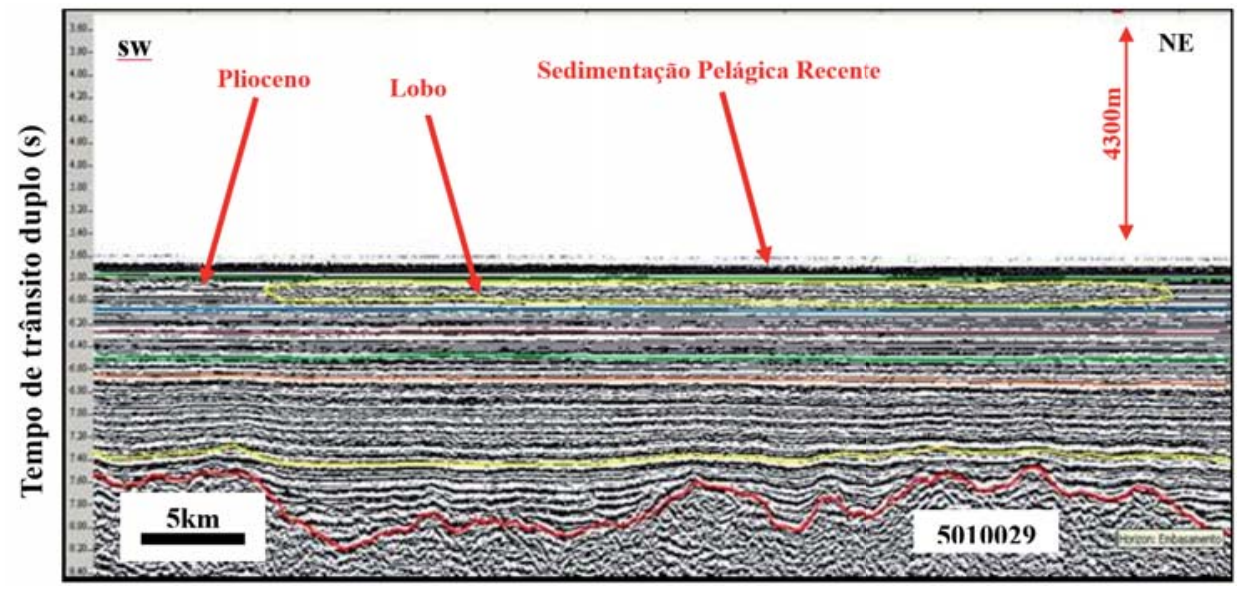

Figura 4 - Visualização da extensão inicial do lobo e sedimentação pelágica recente. 
A conjugação dos seguintes fatores criou as condições propícias à formação da lente: a - Elevação do Ceará, devido a sua localização na porção NE da bacia, servindo de anteparo à sedimentação e à respectiva progressão da sequência; b - o gradiente topográfico, gerado pela formação do cone, propiciando uma rampa na direção SE; e c - rebaixamento relativo do nível do mar, conjugado às direções dos transportes de massas de água.

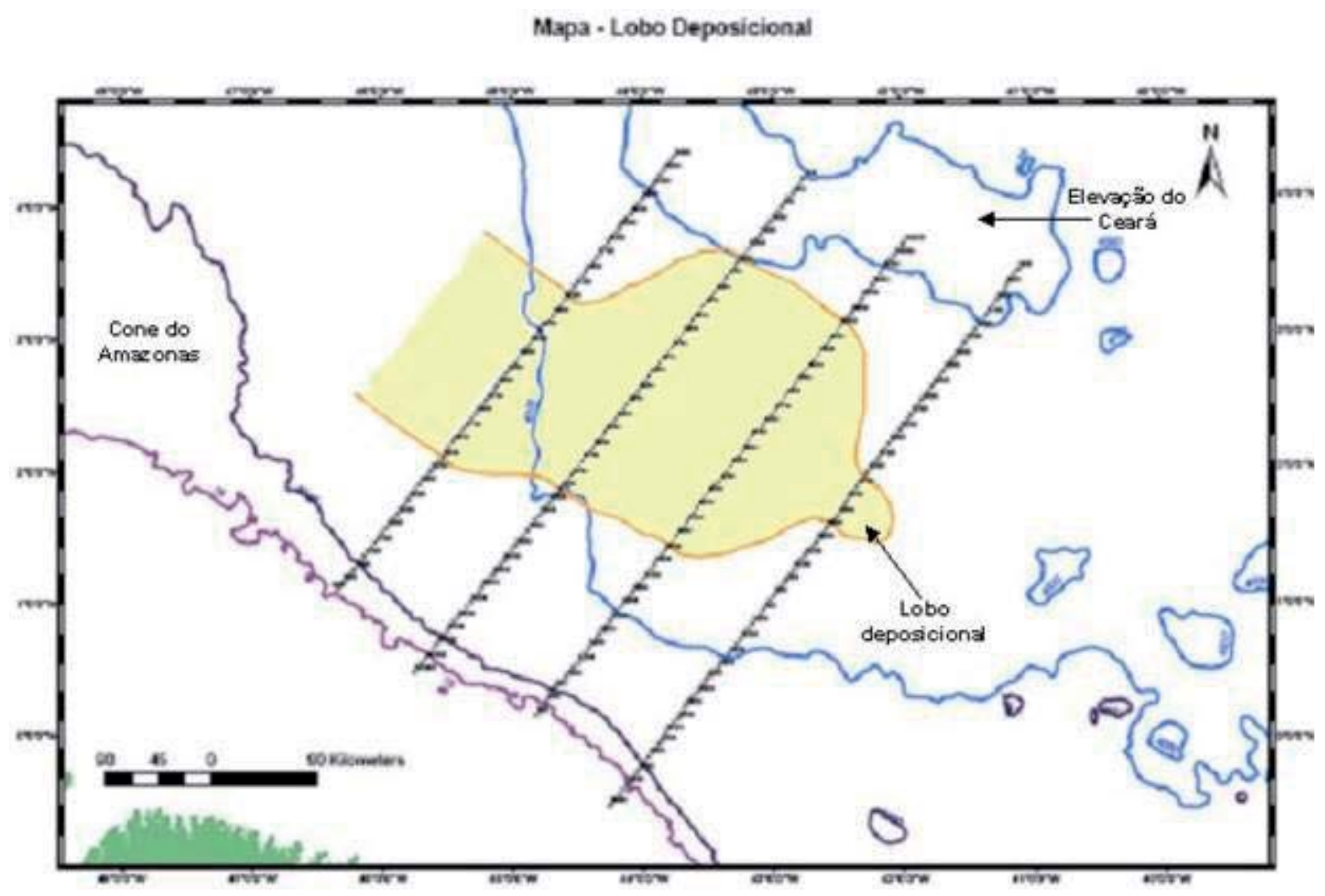

Figura 5 - Mapa da extensão estimada do lobo sedimentar verificado entre os perfis sísmicos.

\section{Descrição e interpretação das estruturas vulcânicas e fundo do mar.}

\section{Perfil 5010029}

Localizado no setor SE da bacia, onde se nota uma intrusão vulcânica, associada à Cadeia de Montes Submarinos (CMS), com apófises cunhando a sequência "Eoceno" na direção SW/NE. A extensão basal da estrutura é de $40 \mathrm{~km}$, a altura do embasamento ao topo é de $8.000 \mathrm{~m}$, sendo $1.300 \mathrm{~m}$ entre o piso marinho e o topo, se considerarmos a velocidade do pulso acústico de $4.500 \mathrm{~m} / \mathrm{s}$ na estrutura vulcânica (Figura 6). Conforme interpretação simplificada de sismofácies distintas, pode ocorrer nos contatos litológicos, uma mistura de rochas vulcânicas, material vulcanoclástico e sedimentos terrígenos/hemipelágicos que estiveram sob alta temperatura.

\section{Perfil 5010030}

Neste perfil observa-se um edifício vulcânico soterrado, com $17 \mathrm{~km}$ de extensão na base e $4.000 \mathrm{~m}$ de altura, localizado na porção distal da bacia e associado à Zona de Fratura São Paulo, (Figura 7), seguido de cinco outras elevações vulcânicas componentes do embasamento, em direção à planície abissal. Estas influenciaram as sequências deposicionais "Cretáceo" e "Paleoceno" assentadas diretamente acima. Na porção proximal da bacia nota-se o segmento da Cadeia de Montes Submarinos (CMS), servindo de anteparo 


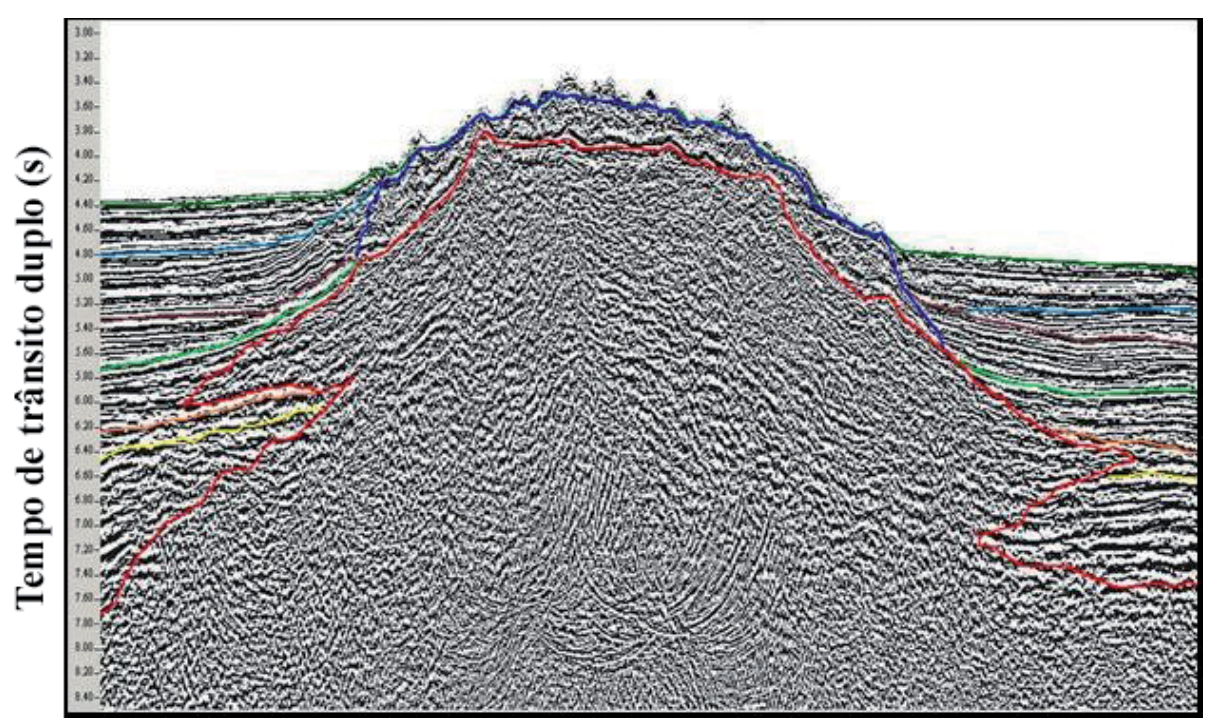

Figura 6 - Estrutura vulcânica associada aos Montes Submarinos.

à sedimentação, em toda a sua extensão de $30 \mathrm{~km}$ de comprimento na base, $8.500 \mathrm{~m}$ do embasamento ao topo e $1.800 \mathrm{~m}$ de altura acima do fundo marinho (Figura 8).

\section{Fundo do mar perfil 30}

Neste perfil observa-se um canal no sopé continental, com $7 \mathrm{~km}$ de largura e $150 \mathrm{~m}$ de profundidade, encaixado entre as montiformas com sismofácies características, distintas em ambos os extremos. A montiforma do lado do sopé apresenta sismofácies contorcidas e caóticas de baixa amplitude e baixa continuidade, características de depósitos resultantes de processos gravitacionais. No outro extremo, a montiforma apresenta sismofácies paralelas onduladas com as mesmas características da última sequência deposicional pliocênica recente. (Figura 9). No interior do canal, sob o piso marinho, a sismofácies apresenta as mesmas características daquelas na montiforma do lado voltado para o sopé. Mediante análise da morfologia e das sismofácies neste trecho, pode-se deduzir que a montiforma situada na porção proximal do sopé, apresentava uma extensão maior do que o tamanho atual, formando um único pacote de sedimentos resultantes de processos gravitacionais, que ao alcançar o contato talude-sopé, teria provocado o enrugamento e consequente convexidade

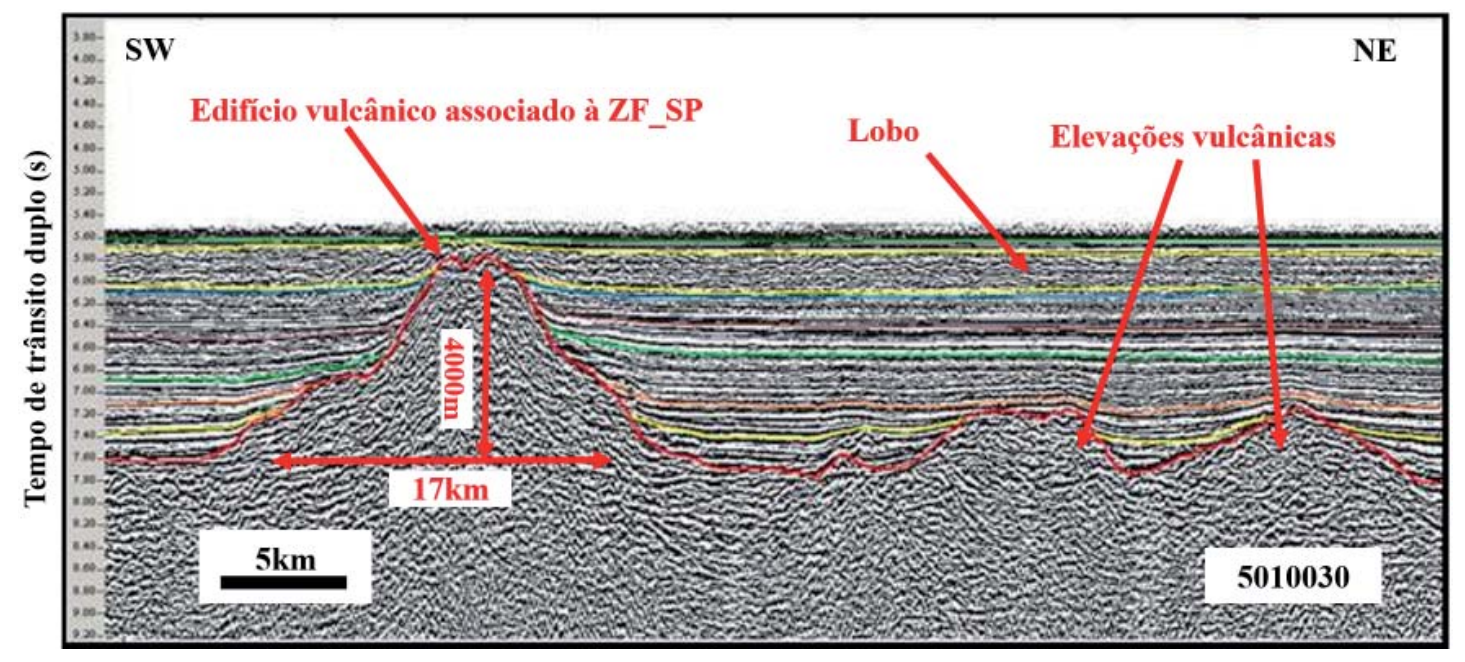

Figura 7 - Edifício, elevações vulcânicas e lobo deposicional. 


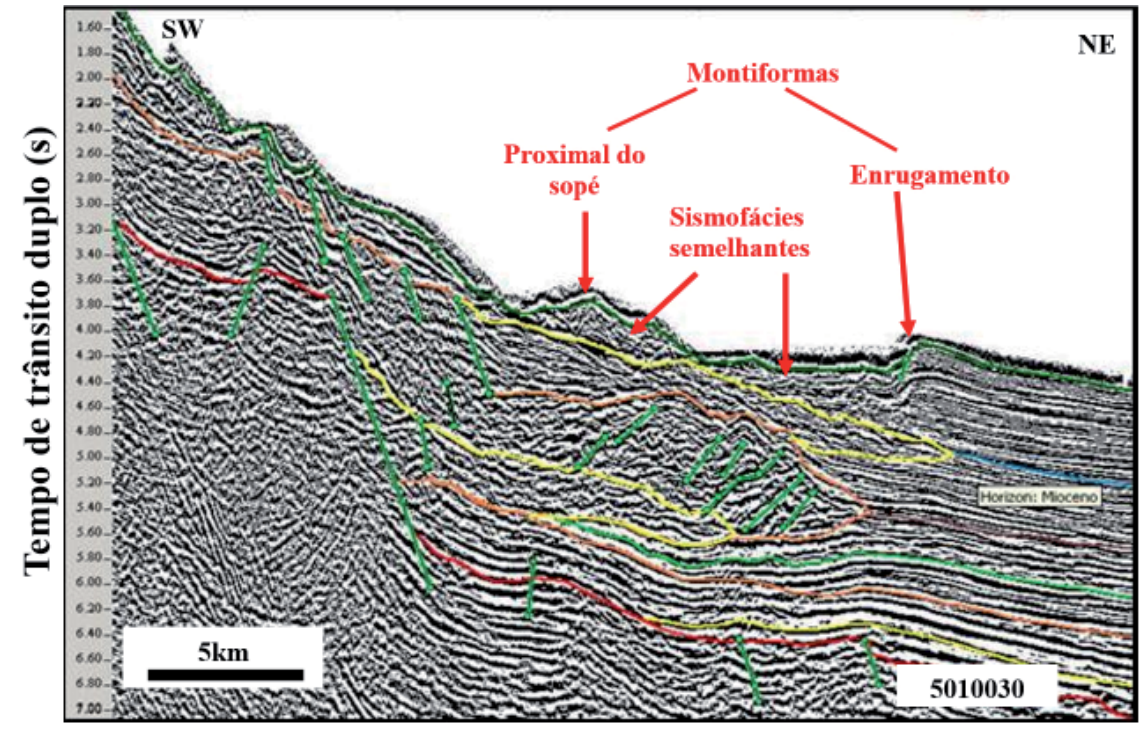

Figura 8 - Cadeia de Monte Submarino servindo de anteparo à sedimentação.

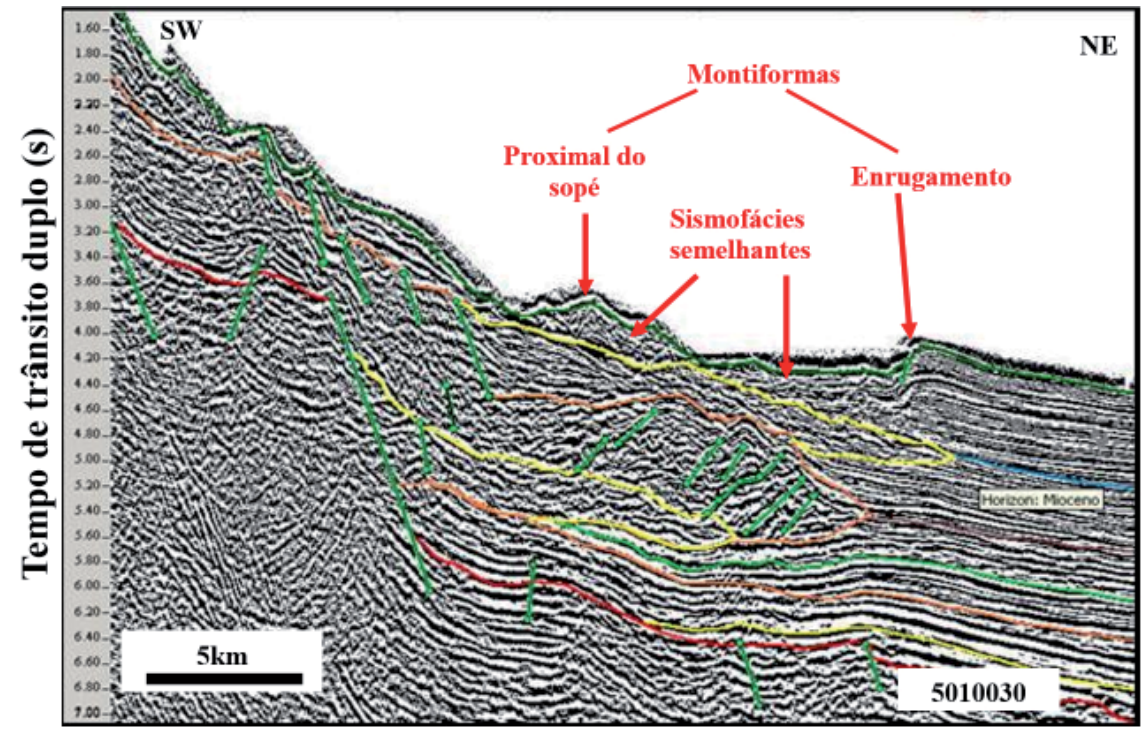

Figura 9 - Montiformas delimitando canal.

dos sedimentos da sequência superior, através da compressão da carga sedimentar sobre a sequência recente.

Com a evolução, sob a atuação de correntes de contorno profundas associada ao rebaixamento do nível do mar, o trecho mediano teria sido remobilizado, restando a montiforma-testemunho observada no sopé do talude (Figura 10). Em direção à planície abissal, o fundo do mar é secionado pela estrutura vulcânica aflorante componente da Cadeia de Montes Submarinos (CMS), seguindo sem alteração e com ligeira inclinação até alcançar a Elevação do Ceará.

\section{Perfil 5010031}

Observa-se neste perfil a elevação vulcânica aflorante com um segmento lateral intrudindo as sequências deposicionais no sentido do talude (Figura 11). Esta elevação apresenta $50 \mathrm{~km}$ de extensão basal, altura de $8.000 \mathrm{~m}$ da base ao topo, sendo $2.000 \mathrm{~m}$ a partir do piso marinho, seguida paralelamente de edifício vulcânico não aflorante que corta as sequências deposicionais do embasamento ao fundo do mar, com extensão basal de $40 \mathrm{~km}$ e altura de $4.500 \mathrm{~m}$, formando uma grande calha com $25 \mathrm{~km}$ de largura na superfície, preenchida por 


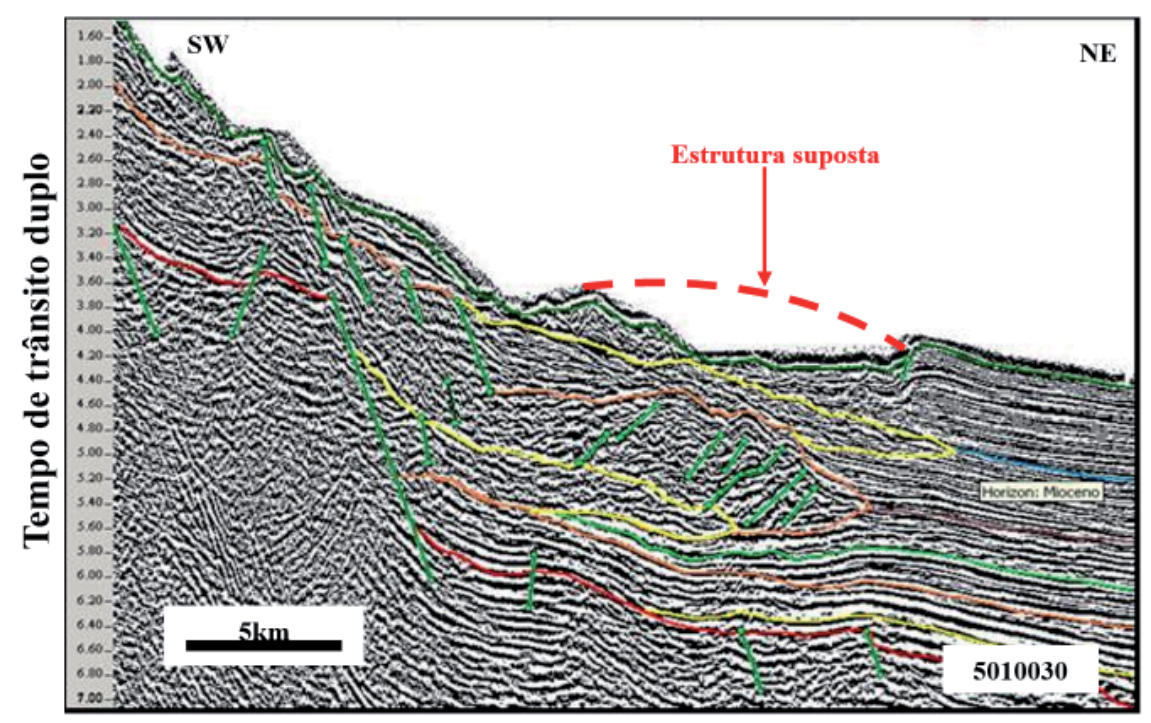

Figura 10 - Morfologia proposta para um suposto evento geológico.

espesso pacote de sedimentos com aproximadamente 4700m. Ambas as estruturas estão associadas também à Zona de Fratura São Paulo.

\section{Fundo do mar perfil 32}

Neste perfil o fundo do mar acompanha as montiformas localizadas no talude. Este com baixa inclinação continua com esta forma em direção à região abissal. Observa-se um canal na região do sopé, com $5 \mathrm{~km}$ de largura e $200 \mathrm{~m}$ de desnível, com topografia suave do lado voltado para o talude, ao passo que, na porção voltada para a região abissal observam-se ondulações provavelmente originadas pelo extravasamento de sedimentos transportados, das porções rasas em direção ao fundo, por processos gravitacionais (Figura 12).
Adiante observa-se a declividade do fundo pouco mais acentuada, associada ao segmento não aflorante da Cadeia de Montes Submarinos (CMS) criando um pequeno degrau com $225 \mathrm{~m}$ de altura. À frente deste degrau, observa-se um canal com $2.100 \mathrm{~m}$ de largura e $75 \mathrm{~m}$ de profundidade.

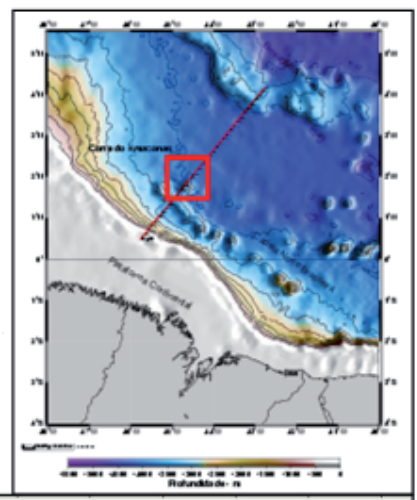

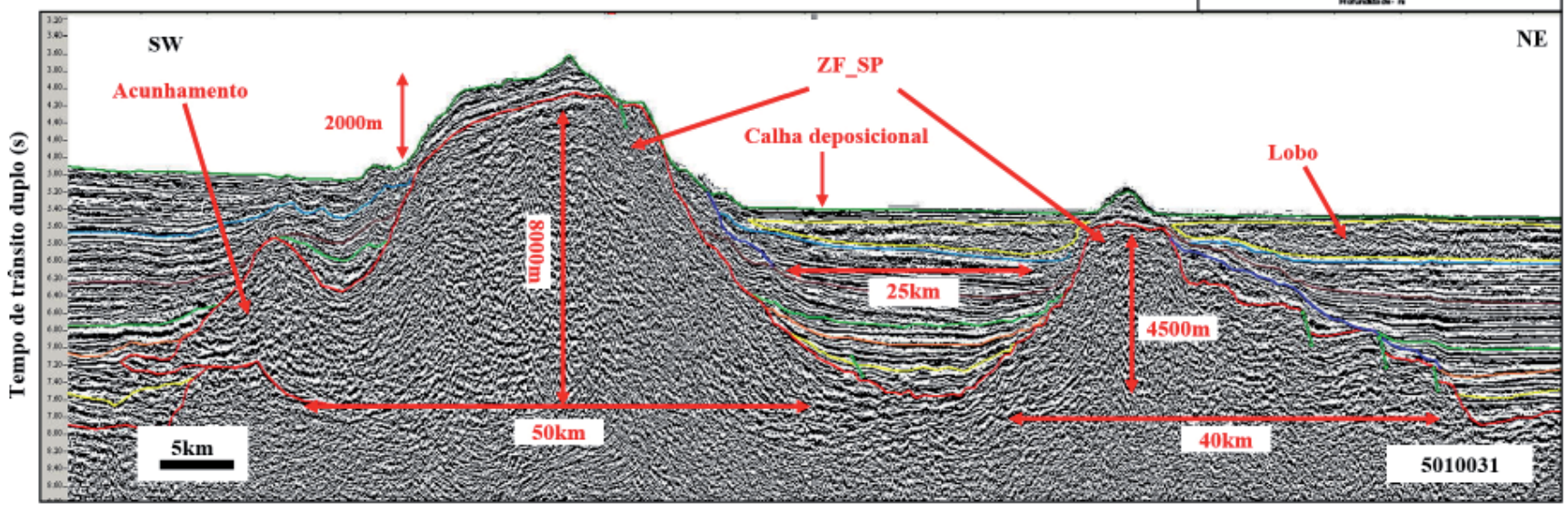

Figura 11 - Estruturas vulcânicas associadas à Zona de Fratura São Paulo. 


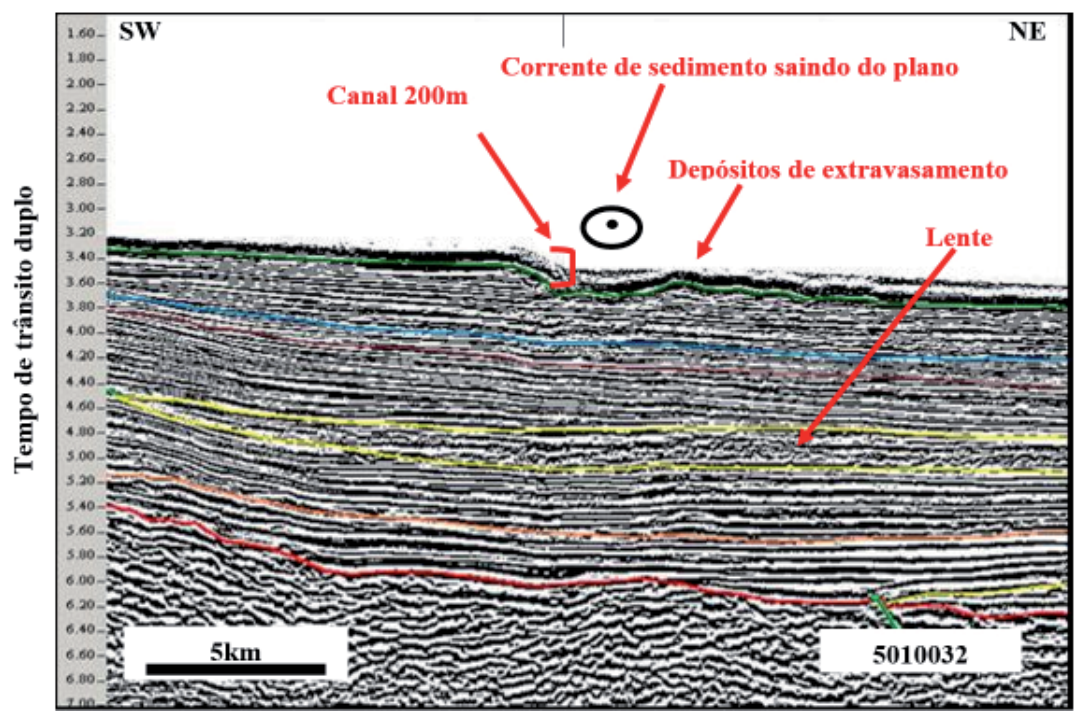

Figura 12 - Canal e depósito de extravasamento, perfil 32 adjacente ao cone do Amazonas. $\odot=$ corrente de sedimentos saindo do plano da figura (norte-sul).

\section{Identificação de refletor e análise de sequências deposicional.}

\section{Sequências Topo do Cretáceo (S1-K - amarela).}

O limite basal desta sequência corresponde ao próprio embasamento oceânico reconhecido por um forte refletor, irregular a bastante irregular, em toda área de estudo. O limite superior é marcado pela discordância do topo do Cretáceo (Figura13). A sequência encontra-se secionada por elevações do embasamento e estruturas vulcânicas que formam a Cadeia de Montes Submarinos (CMS) e a Zona de Fratura São Paulo, adelgaçando em direção às zonas abissais, porém, em nenhum dos perfis analisados esta sequência alcançou a Elevação do Ceará.
Em termos de espessuras sedimentares, de forma geral, todas as sequências apresentam-se mais espessas no setor entre o talude e a Cadeia de Montes Submarinos (CMS). Nele, a sequências possui $750 \mathrm{~m}$ de espessura em média, se considerar-se a velocidade do sinal acústico no sedimento de $2.500 \mathrm{~m} / \mathrm{s}$. Desta estrutura em diante, as sequências prosseguem afinando até alcançarem a Elevação do Ceará, com espessura média de 500 m.

No perfil 5010032 localizado no setor NW da bacia (Figura 1), entre o sopé e o segmento não aflorante da Cadeia de Montes Submarinos (CMS), observa-se um lençol ondulado sotoposto a uma lente bastante pronunciada. O lençol apresenta sismofácies subparalelas de baixa amplitude.

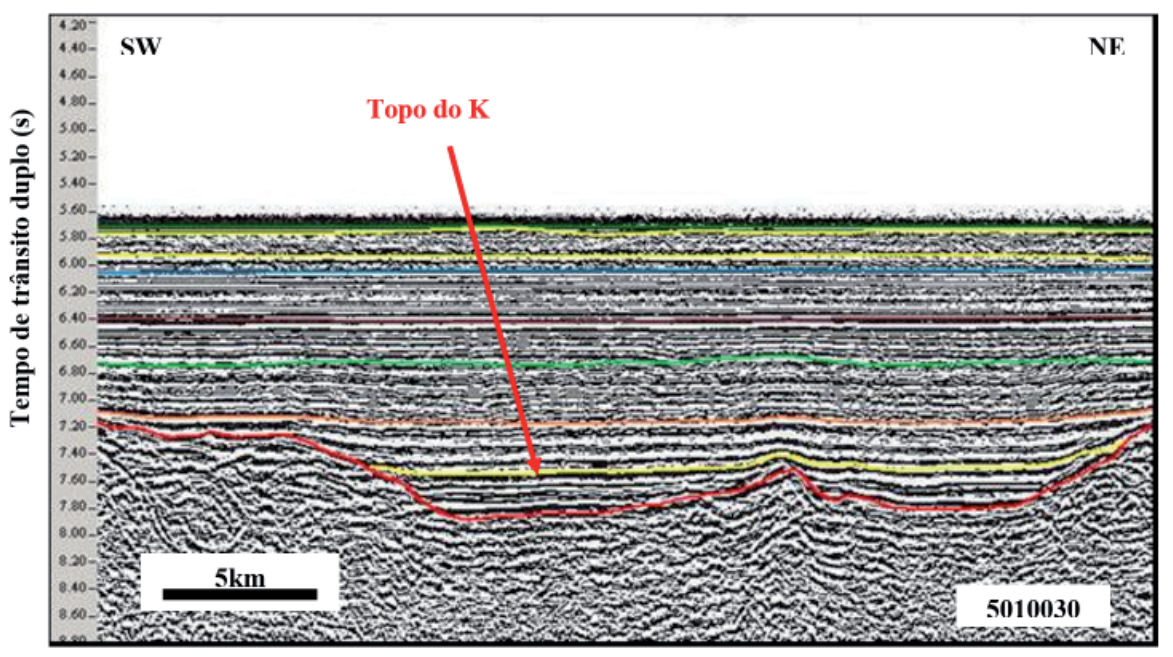

Figura 13 - Topo do Cretáceo, demonstrado pela linha amarela localizada acima da demarcação do embasamento em vermelho. 
A lente é composta de sismofácies semitransparentes caóticas, típicas de ambiente com alta energia e variável. (Figura 14).

Sobre o segmento não aflorante da Cadeia de Montes Submarinos (CMS), encontra-se um complexo de lençóis convexos. No seu interior observam-se dois paleocanais superpostos, o mais antigo, localizado em meio à sequência paleocênica, situa-se próximo do talude e, o mais recente situado bacia adentro, encontrase na altura da sequência eocênica. A migração destes

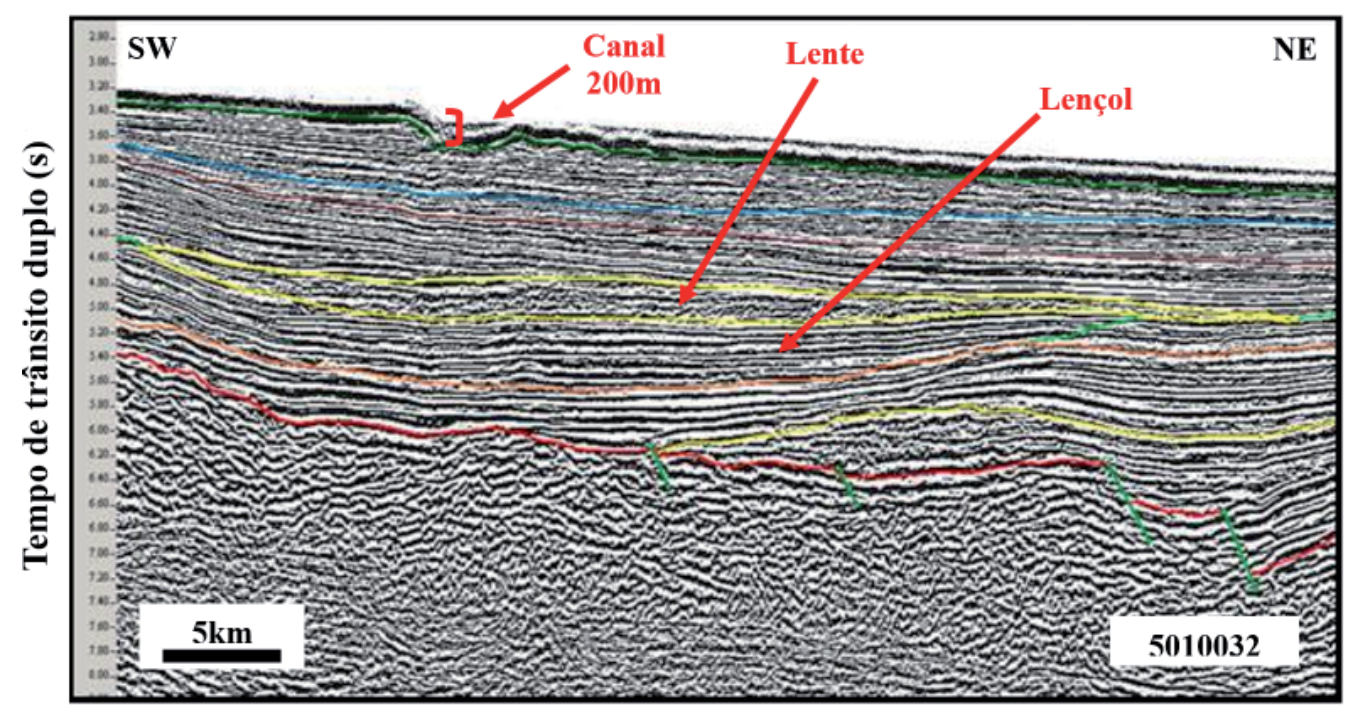

Figura 14 - Morfologia de lente destacada na cor amarela, localizada acima do lençol, ambos adjacentes ao Cone do Amazonas.

canais está intrinsecamente relacionada com a origem do padrão complexo dos lençóis, ou seja, pacotes sedimentares que ora recuam e ora avançam, conforme a oscilação do nível relativo do mar. Após o segmento não aflorante da CMS, observa-se uma configuração divergente, com inclinação progressiva em direção às zonas abissais, influenciadas pelo segmento não aflorante da mesma cadeia. (Figura 15).

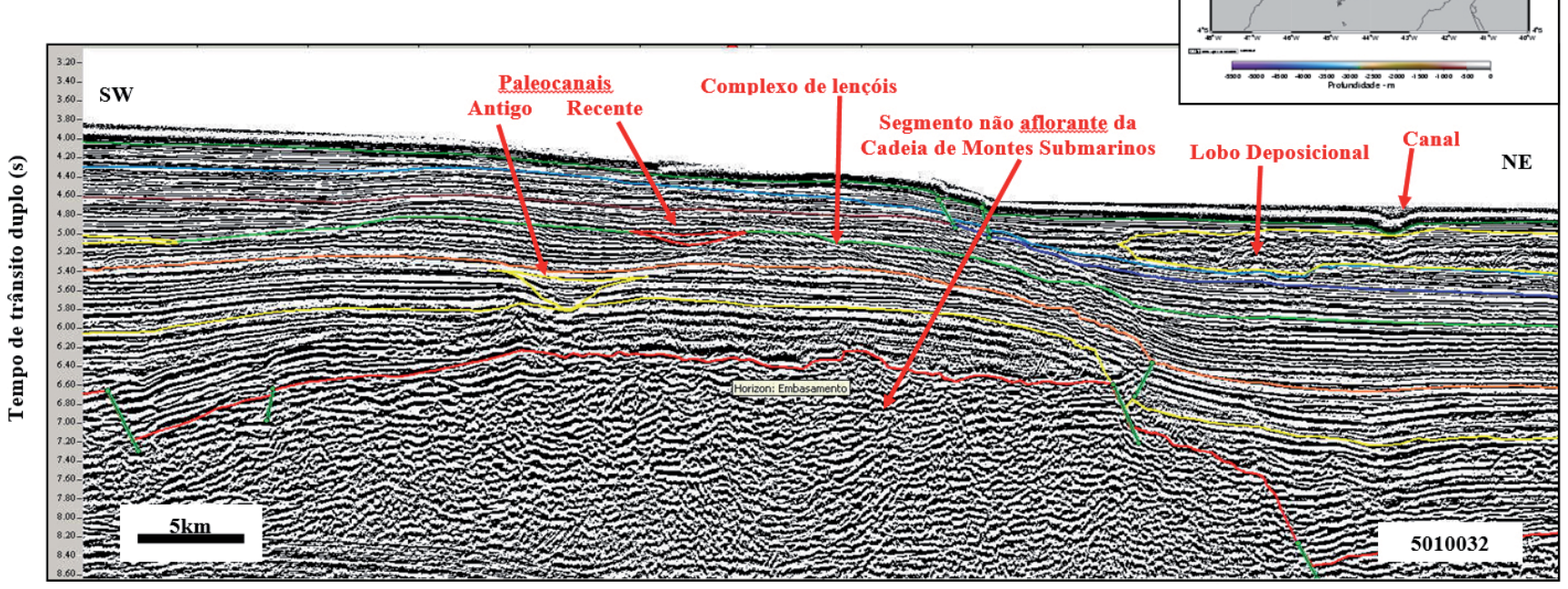

Figura 15 - Segmento não aflorante da Cadeia de Montes Submarinos, paleocanais, complexo de lençóis, lobo deposicional e canal. 


\section{Considerações sobre as correntes de fundo e as fei- ções morfológicas.}

A Cadeia de Montes Submarinos serve de canalizadora e consequente aceleradora das correntes de contorno profundas, uma vez que se forma um corredor entre a mesma e o talude. Esta condição vai influenciar diretamente no transporte e erosão de sedimentos depositados no talude e no sopé continental.

O talude e o gradiente formado a partir do acúmulo de sedimentos do cone do Amazonas, somados à compressão da porção inferior do sobrefluxo da Água de Fundo do Atlântico Norte, induzem à deflexão da Água de Fundo da Antártica em direção à Elevação do Ceará atingindo o flanco oeste da mesma, contornando-a e seguindo para o hemisfério Norte.

\section{Considerações sobre as sequências}

A sequência Cretáceo encontra-se delimitada por uma discordância, gerada provavelmente a partir do rebaixamento do nível relativo do mar ocorrido no limite Cretáceo-Terciário, em torno de 65 Ma, que associado a processos tectônicos, potencializaram a capacidade de remobilização sedimentar das correntes de fundo. Esta superfície foi correlacionada aos limites dos megaciclos Zuni e Tejas por Cainelli (1992), caracterizando o início do superciclo TA1 de Haq et al (1988).

O limite superior da sequência Paleoceno, situa-se em uma posição intermediária entre os rebaixamentos globais do nível marinho que marcam o final dos superciclos TA1 (58,5 Ma.) e TA2 (49,5 Ma.) de Haq et al., (1988). O limite demonstrado como sendo o final desta sequência, encontra-se demarcado no topo do superciclo TA1 (58,5 Мa.)

A partir do Paleoceno-Eoceno Inferior implantase, na porção proximal da área de estudo, um sistema de plataforma e talude marinhos, permitindo a formação de uma espessa unidade carbonática, com calcarenitos finos a médios, bioclásticos, gradando distalmente para micritos argilosos. Esta fase de grande atividade orgânica aliada à subsidência térmica atenua-se sensivelmente a partir do Mioceno Superior (ZANOTTO \& SZATMARI 1987).

A sequência Mioceno, apresenta uma superfície discordante intimamente ligada a flutuações glácio -eustáticas de influência global. Mediante análises de registros de isótopos de oxigênio em foraminíferos ben- tônicos, sabe-se que, pelo menos desde o Eo-Oligoceno, as flutuações do nível do mar vêm sendo controladas por processos de crescimento e derretimento das calotas polares (MILLER et al., 1985 e 1991).

A base da sequência Plioceno pode ser correlacionada ao topo do superciclo TB2 de Haq et al (1988) Mioceno Superior, conforme interpretação de Gomes (2000), caracterizando um dos mais expressivos rebaixamentos do nível relativo do mar em todo Cenozóico, ocorrido em torno de 10,5Ma.

\section{Considerações sobre o processo de tectônica gravi- tacional na área de estudo.}

A estrutura de destaque na área de estudo, localizada a partir da quebra do talude estendendo-se até o sopé continental, observada nas bacias da Foz do Amazonas, Pará-Maranhão e Barreirinhas (Figura 16), foi correlacionada à tectônica gravitacional por Guimarães et al. (1989); Zalán, (1999); Koyi, (2000). Seu mecanismo de formação está intrinsecamente associado a processos de colapsos gravitacionais na plataforma e, compressão na região de crosta oceânica, particularmente em regiões afetadas por zonas de fraturas. Também considera-se a hipótese de uma relação com a movimentação de falhas transformantes e intrusões vulcânicas, bastante comuns no segmento do Atlântico Equatorial. Através da interpretação simplificada realizada pelos autores supracitados, o processo de tectônica gravitacional teria ocorrido no final do Paleoceno/Maastrichtiano e início do Paleoceno/Eoceno, a partir da superfície discordante, limite entre as respectivas sequências, onde ocorre a zona de deslocamento.

No contexto da análise dos perfis, pode-se deduzir que o movimento de massa da área de estudo, não foi gerado a partir de um único evento, pois, nota-se a superposição de seções sísmica, com sismofácies características diferentes demonstrando que ocorreram eventos espaço-temporalmente distintos de basculamentos individuais das seções.

Ressalta-se que a maioria dos movimentos talude abaixo resulta da perda total ou parcial da resistência ao cisalhamento, de modo que, a massa composta por sedimento e água, ao perder a capacidade de resistência ao cisalhamento gravitacional, desloca-se talude abaixo. Essa perda pode ocorrer nas seguintes situações: $\mathbf{a}$ - elevado gradiente do talude; $\mathbf{b}$ - elevada taxa de 


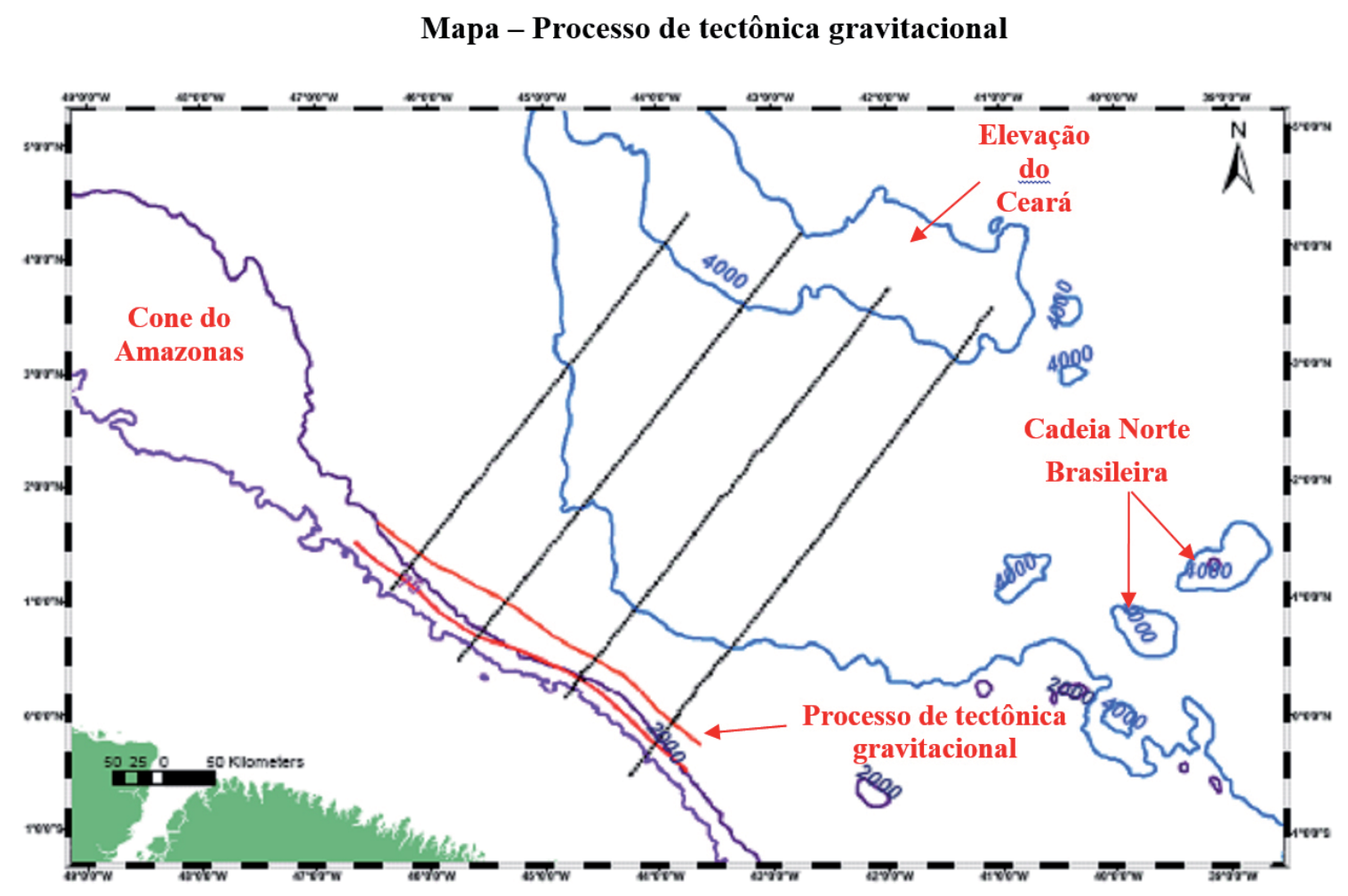

Figura 16 - Mapa da extensão do processo de tectônica gravitacional, destacado em linhas vermelhas, ao longo da isóbata de $2000 \mathrm{~m}$, em meio aos quatro perfis analisados.

sedimentação; c - alívio ou liberação de tensões cíclicas ou repetitivas; $\mathbf{d}$ - elevada produtividade biológica; $\mathbf{e}-$ geração de gás (STOW et al., 1996).

\section{Aplicação do modelo de Varnes ao evento.}

Os deslizamentos de terra tornaram-se um dos principais objetivos do programa da Organização das Nações Unidas para a Educação, a Ciência e a Cultura (UNESCO) no campo das ciências da terra, nos idos da década de 60 . Assim, foi criada uma comissão para estudar e propor mecanismos de mitigação dos danos causados por catástrofes naturais e redução de riscos oriundos destes fenômenos. David J. Varnes compilou e estudou os levantamentos das comissões resultando na elaboração de um modelo publicado em 1978, considerado o mais utilizado nas análises destes eventos, intitulado Slope Movement Types and Processes, no qual apresenta as principais características dos deslizamentos de terra.

A partir do estudo supracitado, procedeu-se a adaptação do evento observado na área de estudo ao modelo proposto por Varnes (1978), com sua respectiva nomenclatura concebida a partir da análise de deslizamentos subaéreo ocorridos em diversas partes do planeta. Segue abaixo as divisões do modelo.

A escarpa principal é uma face íngreme do terreno circundante não rompido na periferia do deslizamento, resultante do movimento do deslizamento fora da superfície. A superfície de ruptura é a projeção desta superfície sob o material perturbado. Material não rompido se limita às porções mais altas da escarpa principal e define a coroa. A cabeça é a porção superior do bloco de deslizamento ao longo do contato entre o material deslocado e a escarpa principal. Os flancos são os lados direito e esquerdo do deslizamento visualizado da coroa para baixo, ou seja, da porção superior do talude em direção ao sopé continental. O corpo principal é o material perturbado que se acomodou sobre superfície de ruptura (onde ocorreu à falha) entre a escarpa principal e o sopé da superfície ruptura (interseção entre a parte baixa da superfície de ruptura e a superfície do terreno original). O sopé é o perímetro de deslocamento do material distante da escarpa principal. 
Varnes (1978) propõe duas zonas principais: a região de depleção, área onde o material perturbado foi retirado e posteriormente depositado abaixo do nível da superfície do terreno original, e a região de acumulação, área onde se encontram as elevações dos materiais perturbados depositados sobre a superfície do terreno original. (Figura 17).

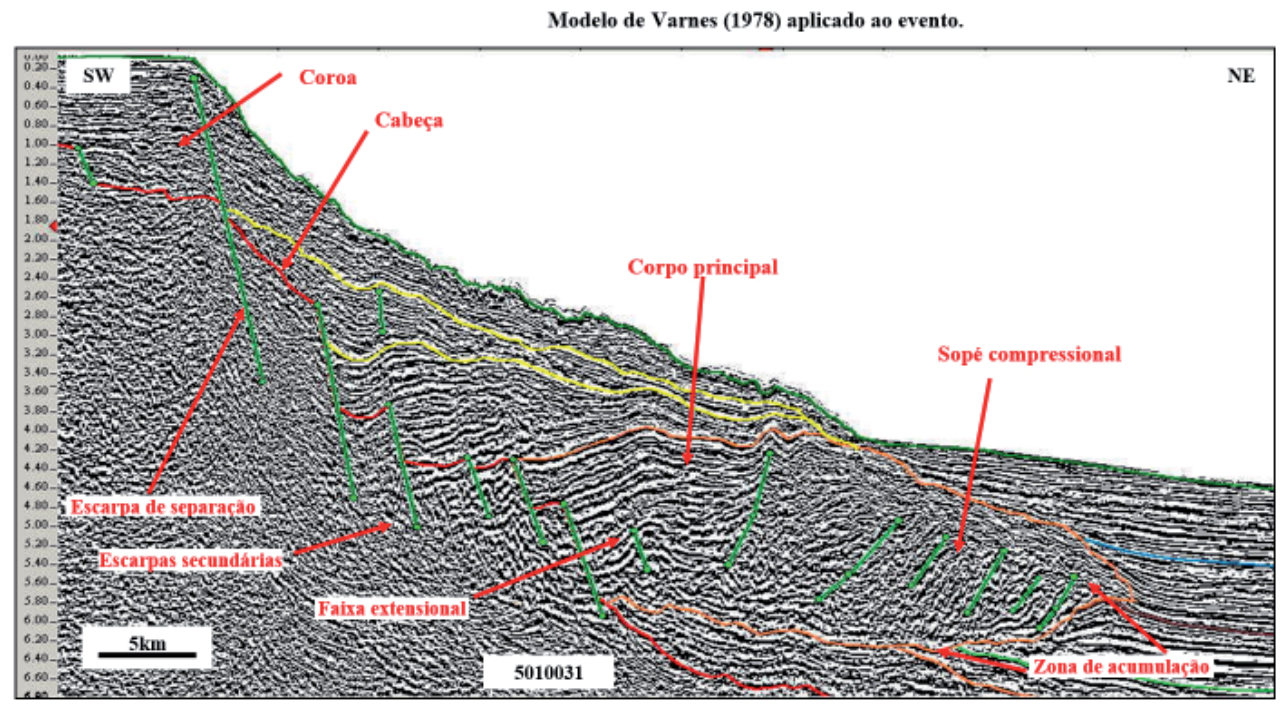

Figura 17 - Principais características do Modelo de Varnes (1978), adaptado ao evento oriundo do processo de tectônica gravitacional encontrado na área de estudo, perfil 5010031.

\section{Conclusões}

Os dados analisados permitem concluir que a topografia da bacia oceânica, conturbada por estruturas vulcânicas, exerce grande influência no deslocamento e distribuição do fluxo das correntes de fundo. As Correntes de Contorno Profundas são aceleradas pelas restrições causadas pelos montes submarinos, desencadeando a erosão do talude, sopé continental e piso marinho. O oposto se verifica na porção da bacia que se estende da Cadeia de Montes Submarinos, paralela à linha de costa, até a Elevação do Ceará, setor da bacia que se encontra sob influência da Corrente de Fundo da Antártica, onde a sismofácies da sedimentação recente demonstra um ambiente tranquilo em relação aos processos deposicionais.

Algumas características encontradas nas sequências mais antigas tais como, superfícies erosivas apresentando cortes repentinos na forma de degraus e paleocanais profundos, também são observadas nas sequências atuais. Estas características são principalmente observadas no perfil adjacente ao cone do Amazonas. Além destas feições são encontradas apófises vulcânicas nos perfis 5010029, 5010030 e 5010031, que acunham os sedimentos na altura das sequências Paleoceno e Eoceno, demonstrando que ocorreram pulsos ou reativação magmática.

Entre a Cadeia de Montes Submarinos e a Elevação do Ceará observa-se uma lente assentada sobre uma expressiva discordância erosiva no topo do Mioceno. Esta discordância pode ter sido originada pela passagem de sedimentos naquele local num evento único, removendo a porção superior da antiga sequência. Este evento ocorreu por ocasião do rebaixamento do nível do mar há 11 milhões de anos. Os sedimentos desta lente são oriundos das rochas pós-arqueanas dos Andes, após a implantação definitiva da Cordilheira, no final do período Neógeno. A morfologia de lente ou "língua", como se fosse um leque de sedimentos seguindo a direção oposta da corrente de fundo, tornou-se possível através da conjugação dos seguintes fatores: o baixo gradiente do fundo, proporcionado pelo Cone do Amazonas; rebaixamento relativo do nível do mar; deflexão da corrente de fundo na direção norte; e maior aporte sedimentar oriundo do Andes.

A morfologia resultante do processo de tectônica gravitacional identificado no talude e sopé continen- 
tal, com $350 \mathrm{~km}$ de extensão longitudinal à costa e 30 - $40 \mathrm{~km}$ de largura e, espessura em torno de 1 a 2,5 $\mathrm{km}$, ocorreu a partir da discordância que dividi o topo do Paleoceno e a base do Eoceno. Sua evolução se deu em estágios atemporais, ou seja, o movimento de massa ocorrido ao longo da borda da plataforma não se deu de uma única vez, e sim, ocorreu sob a forma de eventos sequenciais, evidentes na análise das seções superpostas. Esta circunstância demonstra a ocorrência de colapsos gravitacionais intermitentes, desencadeados por tectônica gravitacional a partir da compressão e dilatação da crosta oceânica, movimentação de falhas transformantes, ou intrusões vulcânicas. Um ou vários destes mecanismos desencadeadores podem não ter cessado, uma vez que os deslizamentos, em menor proporção, continuam ocorrendo na região mesmo sob as condições atuais.

As evidências inferidas ao longo do trabalho permitem concluir que esta região se encontra sob um contexto extremamente dinâmico em termos de processos deposicionais, influenciados pelas correntes de fundo e as antigas estruturas vulcânicas.

\section{Agradecimentos}

Agradecimentos ao LAGEMAR e seus Professores pela infraestrutura de pesquisa e os ensinamentos científicos. Ao CNPq pelo apoio financeiro sob a forma de bolsa.

\section{Referências}

CAINELLI, C. - 1992 - Sequence stratigraphy, canyons, and gravity mass-flow deposits in the Piaçabuçu Formation, Sergipe-Alagoas basin, Brazil. The University of Texas at Austin, Texas. (Tese de Doutorado).

DELLAFÁVERA, J.C. - 2001 - Fundamentos de Estratigrafia Moderna. Ed.UERJ, Rio de Janeiro.

DOBSON D. M., DICKENS. G. R., REA. D. K. - 2001 Terrigenous sediment on Ceará Rise: a Cenozoic record of South American orogeny and erosion. Palaeogeography, Palaeoclimatology, Palaeoecology 165 (2001) p.215-229.

GAMBOA, L.A.P., BUFFLER, R.T., BARKER, P.F. - 1983 Seismic stratigraphy and geologic history of the Rio Grande gap and southern Brazil Basin. In: Barker, P. F. e Johnson, D.A. (eds.) Init. Repts. DSDP, Washington (U.S.Govt. Printing Office), v. 72, p. 481-497.
GOMES, P.O. - 2000 - Distensão crustal, implantação de crosta oceânica e aspectos evolutivos das zonas de fratura e da sedimentação no segmento nordeste da margem continental brasileira. Dissertação de Mestrado - Universidade do Estado do Rio de Janeiro, Rio de Janeiro.

GOMES,P.O., GOMES, B.S., PALMA, J.J. C., JIMMO, K. SOUZA, J.M. - 2000 - Ocean-Continent transition and tectonic framework of the oceanic crust at the continental margin off NE Brazil: Results of LEPLAC Project. In: Atlantic Rifts and Continental Margins - Geophysical Monograph. 115, p.261291.

GUIMARÃES, P.T.M., MACHADO, E.R., SILVA, S.R.P. 1989 - Interpretação sismo-estratigráfica em águas profundas na Bacia do Pará-Maranhão. In: Sintex, Seminário de Interpretação Exploratória, 1 PETROBRAS - Departamento de Exploração, Rio de Janeiro, Anais, p.171-183.

HAQ, B.U., HARDENBOL, J., VAIL, P.R. - 1988 - Mesozoic and Cenozoic chronostratigraphy and eustatic cycles. In: Wilgus, C.K., Hastings, B.S., Kendall, C.G.St.C., Posamentier, H.W., Ross, C.A., e Van Wagoner, J.C. (eds.) Sea level changes - an integrated approach. SEPM Spec. Publ. 42, Tulsa, p. 71-108.

KOYI, H.A. - 2000 - Towards dynamic restoration of geologic profiles: some lessons from analogue modelling. In: Mohriak, W.U., Talwani, M. (eds.). Atlantic rifts and continental margins, AGU Geophysical Monograph 115:p.317-329.

MENDES, J.M.C. - 1994 - Análise estratigráfica da seção Neo-Aptiana/Eocenomaniana (Fm. Riachuelo) na área de Aracaju e adjacências - Bacia de Sergipe-Alagoas. UFRGS. Dissertação de Mestrado, Porto Alegre, RS.

MILLER, K.G., MOUNTAIN, G.S., TUCHOLKE, B.E., - 1985 - Oligocene glacio-eustacy and erosion on the margins of the North Atlantic. Geology, Boulder, v. 13, p. 10-13.

MILLER, K.G., WRIGHT .D., FAIRBANKS, R.G. - 1991Unlocking the ice house: Oligocene-Miocene oxygen isotopes, eustasy, and margin erosion. Journal of Geophysical Research, v. 96, n. B4, p. 6.829-6.848.

MITCHUM, R.M., Jr., VAIL, P.R., THOMPSON, S., III - 1977 - Seismic Stratigraphy and Global Changes of Sea Level, Part 2: The Depositional Sequence as a Basic Unit for Stratigraphic Analysis. In: Payton, C.E. (ed.) Seimic Stratigraphy - Applications to Hydrocarbon Exploration. AAPG Memoir 26, Tulsa, p.53-62.

POAG, C.W. - 1985 - Geologic Evolution of the United States Atlantic Margin. Van Nostrand Reinhold Company, New York. 
POAG, C.W., MOUNTAIN, G.S. - 1987 - Late Cretaceous and Cenozoic evolution of the New Jersei continental slope and upper rise: An integration of borehole data with seismic reflection profiles. In: Poag, C.W., Watts, A.B. et al., Init. Repts. DSDP, Washington (U.S. Govt. Printing Office) v. 95.

SEVERIANO RIBEIRO, H. J. P. - 2001 - Estratigrafia de Sequências. Fundamentos e Aplicações - Editora da Universidade do Vale do Rio dos Sinos RS - Brasil.

SMITH, W. H. F., D. T. SANDWELL - 1997 - Global seafloor topography from satellite altimetry and ship depth soundings, Science, v. 277, p. 1957-1962, 26 Sept.

SOUZA CRUZ, C. E. - 1995 - Estratigrafia e sedimentação de águas profundas do Neógeno da Bacia de Campos, Estado do Rio de Janeiro, Brasil. Tese de doutorado UFRGS.

STOW. D. A. V., READING, H.G., COLLINSON, J.D. - 1996 - Deep Seas. In READING, H.G. (ed) 1996. Sedimentary environments: processes, facies, and stratigraphy. $3^{\text {rd }}$ ed.,
Blackwell Publishing Company.

VAIL, P.R., MITCHUM, R.M., Jr., THOMPSON, S., III - 1977 - Seismic Stratigraphy and Global Changes of Sea Level, part. 4: Global cycles of relative changes of sea level. In: Payton, C.E. (ed.) Seismic Stratigraphy - Applications to Hydrocarbon Exploration. AAPG Memoir 26, Tulsa, p.83-97.

VARNES, D. - 1978 - Slope Movement Types and Processes. In R. L. Schuster (Ed.), Special Report 176: Landslides: Analysis and Control (pp. 11 - 33). Washington, D.C.: National Research Council.

ZALÀN, P.V. - 1999 - Seismic expression and internal order of gravitational fold-and-thrust belts in Brazilian deep waters. In: SBGf, International Congress of the Brazilian Geophysical Society, 6, Rio de Janeiro, Abstract volume, SBGf.

ZANOTTO, O. SZATMARI, P. - 1987 - Mecanismo de rifteamento da porção ocidental da Margem Equatorial, Bacia do Pará-Maranhão. Revista Brasileira de Geociências, 17(2): p.189-195. 